\title{
Diamond ages: what they mean and how they can be interpreted
}

\author{
Steven B. Shirey ${ }^{1}$ and D. Graham Pearson ${ }^{2}$ \\ ${ }^{I}$ Department of Terrestrial Magnetism, Carnegie Institution for Science, Washington DC 20015 USA \\ ${ }^{2}$ Department of Earth and Atmospheric Sciences, University of Alberta, Edmonton AB T6G $2 E 3$ Canada
}

\section{Introduction}

In the 32 years since the landmark paper reporting the first Paleoarchean Sm-Nd ages on garnet inclusions in lithospheric diamonds (Richardson et al., 1984), the understanding of diamond ages has evolved. The advent of single mineral inclusion dating of sulfide with Re-Os (Pearson et al., 1998) and now of garnet and clinopyroxene with Sm-Nd (Timmerman et al., 2016) has provided improved resolution on individual diamond-forming events and has led to the need for a new formalism to interpret mineral inclusion ages and diamond growth. The textural classification of inclusions as protogenetic, syngenetic, or epigenetic simply fails to provide an adequate framework to handle the typical geological variability. Advances in analytical sensitivity, spatial resolution, on the spectral and isotopic composition of diamond itself, and in the geological understanding of cratonic keel evolution now allow us to go beyond the simple textural classification to propose a practical formalism for diamond ages and their uncertainties.

\section{Geochronological types of age determination}

The radiogenic isotopic systems that have been used for diamond age determination have been reviewed by Pearson and Shirey (1999) and Shirey et al. (2013). Although the Ar-Ar method has been applied with some success, the chief methods have relied on the Sm-Nd decay scheme augmented by $\mathrm{Rb}-\mathrm{Sr}$ and the Re-Os system. The most widely applied diamond age determination approach has been the isochron or age array on multiple diamonds from a single mine or alluvial locality. Although with this method there is the potential to combine unrelated diamonds on an isochron that might lead to spurious ages, with enough specimens, multiple generations of diamonds in a single locality can be resolved. The Re-Os system has always permitted single diamond work. The Sm-Nd system, which initially required the combination of groups of inclusions with similar optical properties and/or composition has now moved to the phase where single silicate inclusions can be analyzed (Timmerman et al., 2016).

Single diamonds can be dated in four basic ways: 1) model ages, 2) radiogenic Os ages (common-Osfree), 3) single diamond mineral isochrons, and 4) growth ages. Model ages are produced by the intersection of the evolution line for the inclusion with a reference reservoir such as the mantle. These ages can have large uncertainties (e.g. hundreds of myr) due to uncertainties in the reference reservoir and the lack of the systematic check available from other inclusions (as in the case of isochron ages). These ages are most useful when applied to peridotitic inclusions, although they have been used effectively for very high Re/Os eclogitic inclusions. For instance, occasionally sulfide inclusions have occurred with nothing but radiogenic Os derived from the decay of Re. These are rare, common-Osfree sulfides that yield a highly accurate absolute age in some ways equivalent to a model age (Richardson et al. 2001). The most accurate single diamond age is determined on a diamonds with multiple inclusions. In this case an internal isochron can be obtained that not only establishes equilibrium among the multiple grains but unequivocally dates the time of diamond growth (e.g., Pearson et al., 1998; Westerlund et al., 2006, Smit et al., 2016, Gress et al., 2017). With extreme luck in obtaining the right diamond, growth ages can be obtained from inclusions in concentric diamond growth zones visible in UV fluorescence or cathodoluminescence whose ages decrease outward. These single grains can be extracted to give a minimum growth time for the diamond. Time scales for diamond growth can range from geologically instantaneous (Westerlund et al., 2006) to billions of years (Pearson, 1999; Wiggers deVries et al., 2013). In optimal situations, multiple inclusions are present within single growth zones, in single diamonds, allowing internal isochrons to be constructed for individual growth zones in single diamonds (e.g., Gress et al., 2017).

\section{Geological or mineralogical uncertainties to diamond geochronology}

Due to excessively low trace element concentrations (McNeill et al., 2009), diamond itself can not be dated directly. A gem diamond retains little of the fluid from which it has crystallized -therefore compositional information related to its encapsulated inclusion is lacking. All mineral inclusions in diamonds are miniscule compared to normal mantle xenoliths yielding a small sample that is poorly 
representative of mantle mineralogy. Nestola et al (2014) found that the majority of olivines included in diamonds have no systematic crystallographic relationship with their host. Furthermore, textures alone usually do not permit discrimination between an origin from either the recrystallization of a preexisting mineral in the presence of a fluid (syngenetic) or simple growth around a pre-existing mineral, with likely extensive dissolution of that mineral to reduce the grain size to that of the inclusion (protogenetic). Thus a primary source of geological/mineralogical uncertainty on diamond ages is any process affecting protogenetic mineral inclusions before encapsulation in the diamond, especially if it occurred substantially before diamond formation.

Good examples of inclusion history prior to incorporation exist in the literature. Mineral inclusions such as sulfides situated in metasomatic veins (Liu et al., 2009) are texturally clearly younger than the host rock and document pathways for younger diamond forming fluids. Silicate inclusions such as garnets may display complex trace element patterns indicative of multiple-stage processes of melting and enrichment (Stachel and Harris, 2008). Minerals such as harzburgitic garnet can display low Nd and high Sr isotopic compositions that are antithetical to the typical trace element depletion associated with extreme melting of the subcontinental lithospheric mantle (Richardson, 1984). Multiple sulfide inclusions in one diamond can display different and mass independent sulfur isotopic compositions indicative of unequilibrated solid/liquid phase incorporation (Thomassot et al. 2009), in agreement with the finding of large differences in age between different diamond growth zones (Wiggers de Vries, 2013). Sulfide inclusions can lose Re to fluid or melt at the time of diamond formation leading to strongly unsupported radiogenic Os (Smit et al., 2016). Regional patterns of mineral paragenesis related to large-scale lithospheric structure and crustal magmatism can be established well before diamond growth (Shirey et al., 2002). The new formalism for documenting a diamond age is designed to account for these uncertainties.

\section{Systematic and analytical uncertainties associated with diamond geochronology}

In practical application, the isotopic systems discussed above also carry with them inherent systematic uncertainties. The Re-Os system has a low blocking temperature $\left(\sim 400^{\circ} \mathrm{C}\right.$; Brenan et al. 2000) and its resistance to resetting in the lithospheric mantle depends chiefly on extreme partitioning of Os into sulfide and metal hosts. Discrete sulfides and mono-sulfide solid solutions will exsolve pentlandite and chalcopyrite upon eruption to the surface and exsolution will fractionate parent (Re) from daughter (OS). This necessitates complete grain recovery from the diamond; partial analysis will induce error. Single grain analysis for both silicate $(\mathrm{Sm}-\mathrm{Nd})$ and sulfide (Re-Os) can only produce meaningful results if the sample-to-blank ratios are high enough and may set a practical limit to the minimum size of grain that can be processed. As all diamonds are xenocrysts in their kimberlite hosts, most isochrons or age arrays, whether composed of inclusion composites from multiple diamonds or single inclusions from one diamond, have potentially unrelated diamonds on the isochron, This and the large range in initial Os isotope ratios within the cratonic mantle, prior to diamond formation emphasizes the desirability of analyzing diamonds from single diamond growth zones (as above) or from diamonds that can be shown to have likely formed from the same fluid (e.g., Wiggers de Vries et al., 2013; Smit et al., 2016; Gress et al, this volume).

\section{Practical formalism for diamond ages}

Isotopic equilibrium is the essential condition required for the generation of a statistically robust isochron. Thus, isochron ages from multiple diamonds will record a valid and accurate age when the diamond-forming fluid promotes a large degree of isotopic equilibrium across grain scales, even for pre-existing (protogenetic) minerals. This clearly can and does occur. Furthermore, it can be analytically tested for, and has multiple analogues in the field of dating metamorphic rocks. In cases where an age is suspect, due to any combination of the uncertainties discussed above, an age will be valid if its regression uncertainties can encompass a known and plausible geological event (especially one for which an association exists between that event and the source of diamond-forming fluids) and petrogenetic links can be established between inclusions on the isochron. Numerous examples exist (Jwaneng, Orapa, Kimberley Pool, Ellendale), from individual mines/localities where the age arrays can be associated with a known geological event determined by independent study of crustal magmatism or plate tectonic/geodynamic reconstruction, such as subduction or continental collision. On the larger scale of a terrane or craton, the pattern of age distribution, provinciality, or paragenetic variation relative to large-scale differences in the composition of the lithospheric mantle serves to establish age veracity. These features allow diamond ages to be interpreted using realistic diamond 
growth models that relate to actual geologic events, in the same way that we are able to date metamorphic events in earth's crust.

\section{References}

Brenan, J., Cherniak, D., \& Rose, L. A. (2000). Diffusion of osmium in pyrrhotite and pyrite: implications for closure of the Re-Os isotopic system. Earth Planet. Sci. Lett., 180, 399-413.

Gress MU, Pearson DG, Timmerman S, Chinn IL, Koornneef JM, \& Davies GR (this volume) Three phases of diamond growth spanning $>2.0$ Ga beneath Letlhakane established by Re-Os and Sm$\mathrm{Nd}$ systematics of individual eclogitic sulphide, garnet and clinopyroxene inclusions. 11th International Kimberlite Conference Extended Abstract No. 11IKC-4508

McNeill JCR,Pearson, DG, Klein-BenDavid, O, G.M. Nowell, C.J. Ottley \& I. Chinn (2009). Quantitative trace element analysis of gem quality diamonds. J. Physics: Condensed Matter. 21, $364207,13 \mathrm{pp}$.

Nestola, F., Nimis, P., Agel, R., Milani, S, Bruno, M, Pricipe, M \& Harris, JW (2014) Olivine with diamond-imposed morphology included in diamonds. Syngenesis or protogenesis? International Geology Review, 56, 1658-1667.

Pearson DG, Shirey SB, Harris JW, \& Carlson RW (1998) Sulphide inclusions in diamonds from the Koffiefontein kimberlite, S Africa: constraints on diamond ages and mantle Re-Os systematics. Earth Planet Sci Lett, 160, 311-326.

Pearson DG, \& Shirey SB (1999) Isotopic dating of diamonds. In, Application of radiogenic isotopes to ore deposit research and exploration. Economic Geology Special Volume 12, 143-171.

Richardson SH, Gurney J, Erlank AJ, \& Harris JW (1984) Origin of diamonds in old enriched mantle. Nature, 310, 198-202.

Richardson SH, Shirey SB, Harris JW, \& Carlson RW (2001). Archean subduction recorded by ReOs isotopes in eclogitic sulfide inclusions in Kimberley diamonds. Earth Planet. Sci. Lett., 191, 257-266.

Liu Y, Taylor LA, Sarbadhikari AB, Valley JW, Ushikubo T, Spicuzza MJ, et al. (2009) Metasomatic origin of diamonds in the world's largest diamondiferous eclogite, Lithos 112, 1014-1024.

Shirey SB, Cartigny P, Frost DJ, Keshav S, Nestola F, Nimis P, Perason DG, Sobolev NV, Walter MJ (2013) Diamonds and the Geology of Mantle Carbon. Reviews in Mineralogy and Geochemistry, $75,355-421$.

Shirey SB, Harris JW, Richardson SH, Fouch MJ, James DE, Cartigny P, Dienes P, Viljoen F (2002) Diamond Genesis, Seismic Structure, and Evolution of the Kaapvaal-Zimbabwe Craton. Science, 297, 1683-1686.

Smit KV, Shirey SB, \& Wang W (2016) Type Ib diamond formation and preservation in the West African lithospheric mantle: Re-Os age constraints from sulphide inclusions in Zimmi diamonds. Precamb. Res., 286, 152-166.

Stachel T \& Harris JW (2008) The origin of cratonic diamonds-constraints from mineral inclusions. Ore Geol. Rev., 34, 5-32.

Thomassot, E., Cartigny, P., Harris, J. W., Lorand, J.-P., Rollion-Bard, C., \& Chaussidon, M. (2009). Metasomatic diamond growth: A multi-isotope study (C-13, N-15, S-33, S-34) of sulphide inclusions and their host diamonds from Jwaneng (Botswana). Earth and Planetary Science Letters 282, 79-90.

Timmerman S, Koornreef JM, Chinn IL, \& Davies GR (2017) Dated eclogitic diamond growth zones reveal variable recycling of crustal carbon through time. Earth and Planetary Science Letters, $463,178-188$.

Westerlund K, Shirey SB, Richardson SH, Carlson RW, Gurney JG, \& Harris, JW (2006) A subduction origin for Early Archean peridotitic diamonds and harzburgites from the Panda kimberlite, Slave craton: Implications from Re-Os isotope systematics. Contrib. Min. Pet., 152, $275-294$.

Wiggers de Vries DF, Pearson DG, Bulanova GP, Smelov AP, Pavlushin AD, \& Davies GR (2013) $\mathrm{Re}-\mathrm{Os}$ dating of sulphide inclusions zonally distributed in single Yakutian diamonds: Evidence for multiple episodes of Proterozoic formation and protracted timescales of diamond growth. Geochim. Cosmochim Acta, 120, 363-394. 